\title{
Crimean-Congo hemorrhagic fever: Risk factors and control measures for the infection abatement (Review)
}

\author{
SAADIA ASLAM ${ }^{1 *}$, MUHAMMAD SHAHZAD LATIF $^{1 *}$, MUHAMMAD DAUD $^{1}$, \\ ZIA UR RAHMAN $^{1}$, BUSHRA TABASSUM ${ }^{1}$, MUHAMMAD SOHAIL RIAZ ${ }^{2}$, \\ ANWAR KHAN $^{1}$, MUHAMMAD TARIQ ${ }^{1}$ and TAYYAB HUSNAIN ${ }^{1}$ \\ ${ }^{1}$ National Centre of Excellence in Molecular Biology, University of the Punjab, Thokar Niaz Baig, \\ Lahore 53700; ${ }^{2}$ Department of Chemistry, Government College University, Lahore 54000, Pakistan
}

Received July 3, 2015; Accepted September 18, 2015

DOI: 10.3892/br.2015.545

\begin{abstract}
Crimean-Congo hemorrhagic fever (CCHF) is a vector-borne viral disease, widely distributed in different regions of the world. The fever is caused by the $\mathrm{CCHF}$ virus (CCHFV), which belongs to the Nairovirus genus and Bunyaviridae family. The virus is clustered in seven genotypes, which are Africa-1, Africa-2, Africa-3, Europe-1, Europe-2, Asia-1 and Asia-2. The virus is highly pathogenic in nature, easily transmissible and has a high case fatality rate of $10-40 \%$. The reservoir and vector of CCHFV are the ticks of the Hyalomma genus. Therefore, the circulation of this virus depends upon the distribution of the ticks. The virus can be transmitted from tick to animal, animal to human and human to human. The major symptoms include headache, high fever, abdominal pain, myalgia, hypotension and flushed face. As the disease progresses, severe symptoms start appearing, which include petechiae, ecchymosis, epistaxis, bleeding gums and emesis. Enzyme-linked immunosorbent assay, quantitative polymerase chain reaction, antigen detection, serum neutralization and isolation of the virus by cell culture are the diagnostic techniques used for this viral infection. There is no specific antiviral therapy available thus far. However, ribavirin has been approved by the World Health Organization for the treatment of CCHFV infection. Awareness campaigns regarding the risk factors and control measures can aid in
\end{abstract}

Correspondence to: Dr Bushra Tabassum, National Center of Excellence in Molecular Biology, University of the Punjab, 87 West Canal Bank Road, Thokar Niaz Baig, Lahore 53700, Pakistan

E-mail: bushra.cemb@gmail.com

*Contributed equally

Abbreviations: CCHF, Crimean-Congo hemorrhagic fever; CCHFV, CCHF virus; BSL, biosafety level; KPK, Khyber Pakhtunkhwan; ELISA, enzyme-linked immunosorbent assay; qPCR, quantitative polymerase chain reaction; Ig, immunoglobulin

Key words: Crimean-Congo hemorrhagic fever, Crimean-Congo hemorrhagic fever virus, Pakistan, risk factors, control measures reducing the spread of this disease to a greater extent, particularly in developing countries.

\author{
Contents \\ 1. Introduction \\ 2. Virology \\ 3. Vector \\ 4. Transmission \\ 5. Clinical symptoms \\ 6. Scenario of CCHF in Pakistan \\ 7. Risk factors \\ 8. Control measures \\ 9. Diagnostic tests \\ 10. Treatment \\ 11. Conclusion
}

\section{Introduction}

Crimean-Congo hemorrhagic fever (CCHF) is a lethal viral infection of medical significance. It is widespread throughout the world and is most common among tick-borne viral diseases. Ticks of the genus Hyalomma are transmission agents of the $\mathrm{CCHF}$ virus (CCHFV) in humans. The virus is maintained in tick species through horizontal and vertical transmission and spreads to domestic animals, which further carry the disease to humans. Therefore, it is a zoonotic disease (1-4). CCHFV evolved 3,100-3,500 years ago (5). In 1944, the disease was first reported in Crimea, and was therefore assigned as Crimean hemorrhagic fever. In 1969, the same disease was reported in the Congo region, resulting in its current name: 'Crimean-Congo hemorrhagic fever.' Previous studies have observed that the disease is widely distributed in different regions of the world, including Africa; Asia; central southern Europe; eastern Europe, particularly in the former Soviet Union; throughout the Mediterranean; in north-western China; the Middle East; and the Indian subcontinent $(2,6)$. Since 2002, the virus has also shown its emergence in several countries of the Balkans, leading to the concern that $\mathrm{CCHF}$ is expanding in its current geographical distribution (7). The virus is clustered among seven genotypes; 
Africa-1, Africa-2, Africa-3, Europe-1, Europe-2, Asia-1 and Asia-2. These seven genotypes are characterized on the basis of genetic variation in small segments of RNA $(8,9)$. The CCHF is severe as it causes serious medical problems and also results in fatalities when not treated. The disease can be described mainly as the presence of blood in sputum, gums, rectum and urine (10). Another cause for concern is that CCHFV is highly pathogenic in nature, easily transmissible and has a high case-fatality rate of $10-40 \%$. Due to the highly pathogenic nature of CCHFV, the culture of the virus is only permitted in biosafety level four (BSL-4) and in maximum secured laboratories; there is a possible risk of this virus being used as an agent of bioterrorism or as biological warfare $(7,11-14)$.

As the virus has a widespread geographical distribution, it must be recognized as a global health threat. Pakistan has also been experiencing this epidemic disease, covering almost all four of the Punjab, Baluchistan, Khyber Pakhtunkhwan (KPK) and Sindh provinces. Administering preventive measures is urgently required to eradicate the virus from the country, as subsequent to poliovirus, CCHFV may become a serious challenge for the country (15).

In the present review, virology, vector, transmission pathway of the virus, risk factors and control measures are discussed with regards to the current literature to minimize the impact of infection in Pakistan. In additional, the clinical symptoms, diagnostic tests and treatment for this epidemic disease are briefly described.

\section{Virology}

CCHFV belongs to the genus Nairovirus and family Bunyaviridae (7). The genus Nairovirus contains $\sim 34$ tick-borne viruses and these are categorized into seven serogroups (16). The circulation of CCHFV is dependent upon the distribution of ticks, mainly of the Hyalomma genus $(1,17)$. The virus is spherical in shape with a diameter of $80-100 \mathrm{~nm}$, the lipid envelope is $5-7 \mathrm{~nm}$ thick and glycoprotein spikes are $8-10 \mathrm{~nm}$ in length (18). The genome consists of single-stranded RNA with negative polarity, divided into three segments: Small, medium and large segments. These three segments form a complex with nucleocapsid proteins to become a ribo-nucleocapsid. The virion contains three structural proteins: i) A nucleocapsid protein, ii) glycoproteins ( $\mathrm{Gn}$ and $\mathrm{Gc}$ ) and iii) a large polypeptide protein, which is a virion-associated RNA-dependent RNA polymerase with a size of $200 \mathrm{kDa}(13,19)$. The structural features of the virus are shown in Fig. 1.

\section{Vector}

CCHFV is mainly tick borne and is also found in one biting midge species (Culicoides spp.). The virus has been isolated from two different families of tick: Argasidae (soft ticks) and Ixodidae (hard ticks) (20). The transmission cycle runs between tick to vertebrate and again to tick. Vertical and horizontal transmissions involve tick and domestic/wild-live stocks causing them to become viremic without any disease symptoms. Migrating birds can easily carry infected ticks and act as a source of virus dispersal (21). CCHFV occurrence has been reported in $>30$ species of ticks belonging to different genera. Ticks of Hyalomma genus are considered as the major

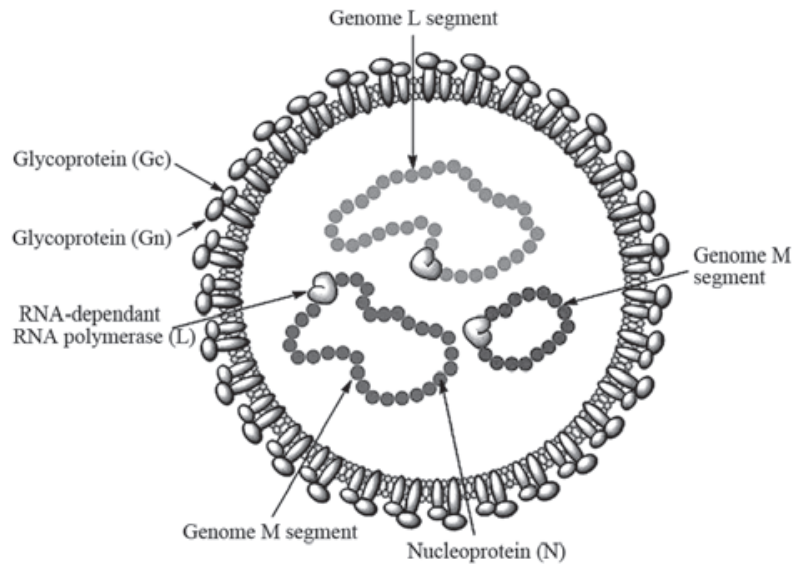

Figure 1. Crimean-Congo hemorrhagic fever virus structure.

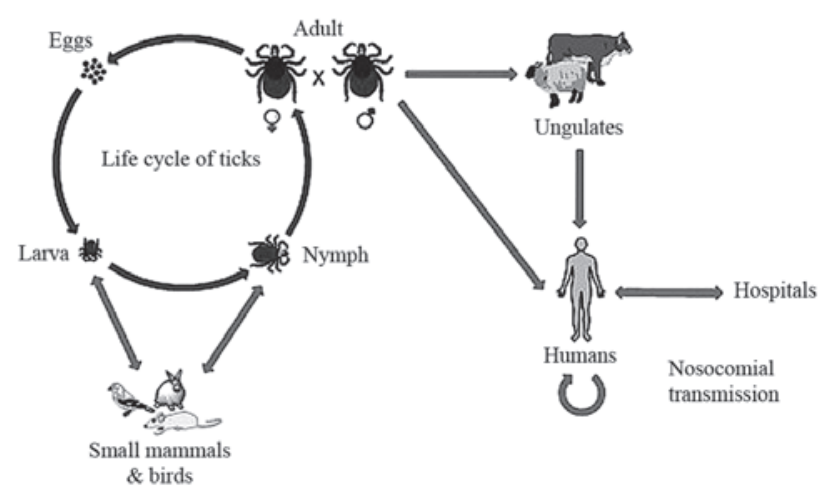

Figure 2. Life cycle of the tick and transmission pathway of Crimean-Congo hemorrhagic fever virus (CCHFV). Subsequent to hatching, larvae find a small animal as its host for its blood meal. Following engorgement, molting of the nymph into an adult occurs and they drop off from their host. Following this, these adult ticks find a large animal for feeding, and mate while attached to their host. CCHFV is transmitted from infected ticks and animals to humans, and from humans to humans in hospitals (nosocomial transmission).

vector for human infection; however, in Kazakhstan, the Dermatocentor niveus ticks are also considered as vectors (22).

\section{Transmission}

Transmission can be from person to person, through contact with infectious body fluids of the infected person and contact with animal blood or products. The life cycle of ticks and the transmission pathway of CCHFV is shown in Fig. 2. The Hyalomma genus ticks are the reservoirs and vectors of the CCHFV. The larvae and nymphs of two-host ticks of this genus feed on hares and small birds feeding on the ground, while at the adult stage they obtain their nutritional requirements from cattle, sheep and certain large mammals. There are certain other Hyalomma species, which are three-host ticks as they drop off their host following each molt (3). Another factor responsible for the transmission of CCHF is the migration of infected livestock populations from infected areas to new areas (23).

Vertical transmission. While shifting from larva to the adult stage during metamorphosis, tick vectors support the replication of the virus present inside their body tissues. Following this, the virus is transmitted to eggs and adult females from 
adult females and adult males, respectively (24-27). In the mid-gut lining of the tick, the virus replicates and finally disseminates to different body tissues, for example, reproductive organs and salivary glands (28). Therefore, through transovarian transmission, thousands of infected eggs are being produced, which are sufficient enough to maintain a large population of infected ticks (29).

Horizontal transmission. During the summer and spring months (June-October), the spread of CCHFV between ticks and animals is higher when larvae and nymphs develop into the adult form by taking the blood meal for their growth. A bite of the infected tick to their host, i.e., small vertebrates, results in transmission of the virus from the tick to their host, and subsequently, healthy ticks feeding on the same host followed by virus replication in host tissue and its circulation in the bloodstream. Previous studies have revealed that all the mammals are not susceptible to infection by CCHFV $(27,30)$.

Non-viremic transmission. This is another type of viral transmission that does not require an animal to be viremic, but directly transfer from the infected to healthy ticks feeding together. During co-feeding, viral substances present in the saliva of ticks accelerate the viral transmission (31-33).

Transmission to birds. Birds are commonly resistant to becoming viremic. No specific antibodies are detected in 37 different species of birds infected with the virus, as CCHFV do not rely on birds as a host for its replication (34).

Transmission to humans. Humans are considered as the dead-end host of CCHFV. CCHFV infection is most common in rural areas where exposure to ticks is high and people become infected when bitten by infected ticks. Physical contact with infected bodily fluids or blood can transmit the virus from person to person within 7-10 days of illness. Transmission can also occur by contact with infected animal blood. This type of transmission is extremely common in butchers' shops (3).

\section{Clinical symptoms}

There are mainly four different phases that are involved in the infection of the CCHFV: Incubation period (non-symptomatic phase), pre-hemorrhagic, hemorrhagic and convalescent (symptomatic phases). The incubation period lasts from 3-7 days of infection. The disease starts with the pre-hemorrhagic period for 4-5 days. The major symptoms include headache, high fever, abdominal pain, myalgia, hypotension and flushed face (10). As the disease progresses, severe symptoms starts appearing including petechiae (red spots on skin), ecchymosis (extravasation of blood), epistaxis (nose bleeding), gum bleeding and emesis (35-37). Nausea, diarrhea, emesis, neuropsychiatric and cardiovascular changes can be additional symptoms (20). When the disease is not treated, patients may succumb due to multiorgan failure. The convalescent period begins in survivors after 10-20 days of illness (16). Full recovery can take a complete year in survivors of CCHF (1).

\section{Scenario of CCHF in Pakistan}

Due to its name, there is confusion surrounding the prevalance of the virus outside of the Congo; however, it has been

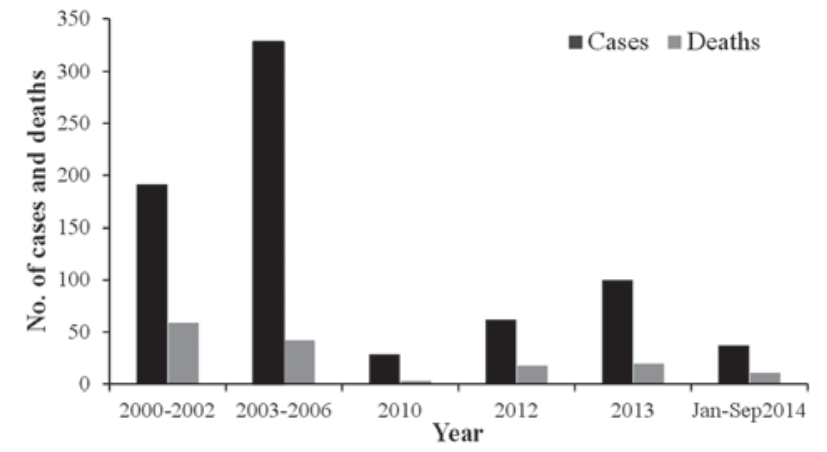

Figure 3. Annually reported cases of Crimean-Congo hemorrhagic fever and resulting deaths in Pakistan.

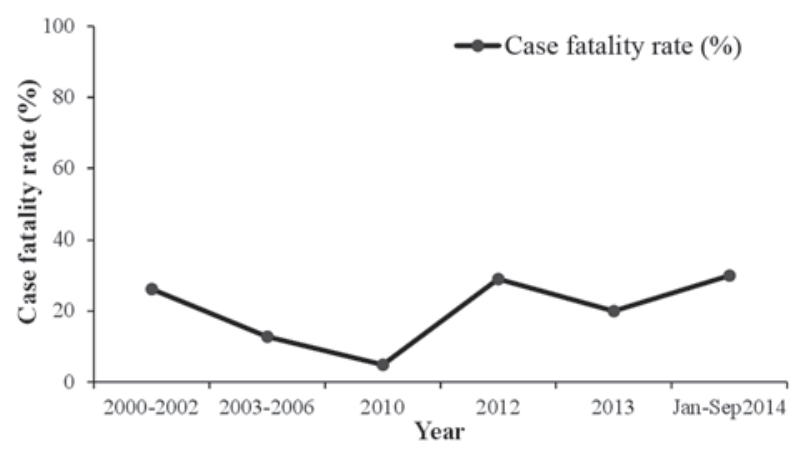

Figure 4. Annual case fatality rate (\%) of Crimean-Congo hemorrhagic fever in Pakistan.

reported in Pakistan and the 'Congo virus is a reality in the country', as stated by Dr Muhammad Najeeb Khan Durrani, a Senior Surveillance Coordinator of Communicable Diseases in Islamabad (38). In Pakistan, the virus was first isolated from the Hyalomma tick species in 1960 (39). Since then, sporadic cases and repeated outbreaks have been observed mainly in people who deal with livestock (40). The most prevalent genotype of CCHFV in Pakistan is Asia-1; however, in Baluchistan the Asia-1 and Asia-2 genotypes have been reported (8). In 1976, at a general hospital of Rawalpindi, a person suffering from abdominal pain and hematemesis (blood vomiting) was reported to be the first case of $\mathrm{CCHF}$ in Pakistan (41,42). According to published studies of $\mathrm{CCHF}$ between 1976 and 2000, there were 23 cases of CCHF in Pakistan with a case fatality rate of $39 \%(12,43)$. From 2000 , a significant increase in $\mathrm{CCHF}$ cases was observed, with 50-60 cases reported annually. In general, there is usually a biannual surge of cases in the country appearing in June and October, at its peak in association with the life cycle of the tick (44). The country experienced an outbreak of CCHF in 2012 when there were 61 suspected cases with 17 fatalities and a $27.8 \%$ case-fatality rate. The disease was mainly prevalent in the province of Baluchistan; however, cases were also reported in Sindh, KPK and Punjab (45). Another outbreak of the virus was reported on September 7, 2013 in Haripur when four butchers succumbed due to working with the meat of an infected sheep (38). In 2014, confirmation of the virus in Baluchistan triggered a further requirement to improve the management of the virus (46). The annual suspected 
cases and the case fatality rate are shown in Figs. 3 and 4, respectively.

\section{Risk factors}

The virus can be transmitted from person to person through contact with animal blood or products, contact with infectious body fluids of an infected person and by handling the infected ticks (47). The areas outside the range of tick distribution are at little or no risk of exposure to ticks. Crushing and rubbing the infected tick on skin or slaughtering the infected animal is also one of the main risk factors towards the exposure of CCHFV. Another well-documented risk factor is nosocomial infection. This is most common among health care workers, particularly during the hemorrhagic period of the disease $(48,49)$. As previously reported, this factor was exemplified in January 1976, when at Central Government Hospital Rawalpindi (Pakistan), a nosocomial incident occurred $(10,43)$, in which the infection was transmitted from a shepherd to a female physician, a surgeon, an assistant surgeon and other health workers. In South Africa at the Tygerberg Hospital, another nosocomial outbreak occurred in which $33 \%$ of the health workers developed CCHF by accidental contact with the patient through a needle prick, and $8.7 \%$ were infected through contact with the blood or other body fluids of the patient. Droplet-respiratory route of infection is also counted as one of the risk factors of CCHF (13). This is supported by several cases of laboratory-acquired CCHF in Africa. Laboratory personnel dealing with viral samples are also highly likely to develop the disease, as supported by numerous cases of $\mathrm{CCHF}$ acquired from a laboratory in Africa (50). For all these reasons, CCHFV has been characterized as a BSL-4 pathogen in the United States by the Center for Disease Control and Prevention (51).

\section{Control measures}

As the life cycle of the tick remains unnoticed in animals, control of CCHF infection in animals and ticks is difficult. The infection is not usually apparent in animals, and only viremia occurs (20). There is no vaccine available, the only way to reduce the infection is by creating public awareness regarding the risk factors of the disease and possible preventive measures, which aid in reducing the exposure to the virus and controlling the spread of the disease.

The risk of the tick to human transmission can be minimized by avoiding areas with a high prevalence of ticks and undertaking special precautions in the most active season of ticks. People who are in high-risk occupations (such as butchers, veterinarians and shepherds) should undergo every possible measure to avoid exposure to virus-infected ticks or virus-contaminated animal blood and other tissues. For instance, the use of gloves and minimal exposure of naked skin to fresh blood animal and other tissues are effective control measures. Similarly, medical workers caring for suspected patients of CCHF should adopt standard barrier nursing techniques. Unpasteurized milk should not be utilized. Only properly cooked food should be consumed, as this kills the viruses. Treating the livestock with acaricides is effective in decreasing the population of infected ticks. The use of commercially available insect repellents, including diethyl toluamide on naked skin is also protective against tick bites. Clothes should be treated with permethrin spray, as it also shields against tick bites (20).

For reducing the risk of animal to human transmission, quarantine measures should be taken while importing animals and they should be treated with pesticides regularly. Maintenance of hygienic conditions during slaughtering, butchering and culling procedures in slaughterhouses or at home is mandatory. Gloves should be worn during the handling of meat. Following the slaughter of an animal, the utensils and other equipment should be washed prior to reuse (14).

To reduce the risk of human-human transmission, close physical contact with the infected person should be avoided. Hands should be washed properly and regularly subsequent to visiting and caring for ill people (14). In certain developed countries, it is recommended that health care workers must use high efficiency air respirators (52); however, this practice is not feasible in a country such as Pakistan (53). Face shields, safety goggles and surgical masks should be used when coming into contact with the patient from three feet away $(54,55)$. Isolation of the patient and barrier nursing is also recommended.

Disposal of used instruments and equipment, including needles, syringes and employing safe burial practices, should be implemented (56). Disinfectants, including $2 \%$ glutaraldehyde and $1 \%$ hypochlorite, can inactivate the CCHFV by heating at $56^{\circ} \mathrm{C}$ for $30 \mathrm{~min}(16)$.

\section{Diagnostic tests}

Diagnosis at an early stage is indispensable to prevent further transmission of the infection. There are different techniques for the infection diagnosis, including enzyme-linked immunosorbent assay (ELISA), quantitative polymerase chain reaction (qPCR), antigen detection, serum neutralization and isolation of the virus by cell culture $(14,57)$. At the Bernhard-Nocht-Institute for Tropical Medicine (Hamburg, Germany), scientists have experimented with certain test systems for the detection of infection with CCHFV. All the tests use ELISA for detecting pathogen-specific immunoglobulins (Ig); human IgM or IgG blood serum antibodies. Tests were based on specific monoclonal antibodies. The hybridoma cell lines were offered for co-development of diagnostic test systems using ELISA or other technology platforms (58). The patients of CCHF are viremic in 7-10 days of disease, and by the end of the first day, weak IgM becomes detectable followed by $\operatorname{IgG}(3)$. The viral antigen can also be visualized in formalin-fixed tissues by immunohistochemical staining (59). The screening tests are available in the majority of diagnostic labs in Pakistan, including the Islamabad Diagnostic Center, Chughtais Lahore lab, Centre of Excellence in Molecular Biology, Lahore and Shoukat Khanum Memorial Cancer Hospital. Reliable and sensitive diagnostic tests, including ELISA and qPCR, provide an essential tool for viral detection and are helpful in minimizing the impact of infection.

\section{Treatment}

The treatment for CCHF viral infection mainly depends on the severity and symptoms of disease. Currently, there is no antiviral drug against CCHFV that is approved by the Food 
and Drug Administration (60). However, ribavirin (Virazole) is the only antiviral drug used against CCHFV, which is only effective in certain cases (61). Despite the verified insufficient efficacy of ribavirin for CCHF patients by two systematic reviews and meta-analyses, the World Health Organization has approved antiviral ribavirin for treatment of $\mathrm{CCHFV}$ infection based on in vitro data $(7,60,62,63)$. Ribavirin can be taken orally and intravenously. For effective results, ribavirin is used along with supportive therapy, such as interferons (16). In numerous in vitro studies, interferon type-I is shown to have antiviral activity, however, no clinical data is available on interferon use $(60,64)$. A recent study utilized modified vaccinia virus Ankara (attenuated poxvirus vector) to develop a recombinant vaccine that expresses glycoproteins of CCHFV in two mouse strains. A cellular and humoral immune response was confirmed against this vaccine, which protected the recipient model animals from developing the lethal disease (61). Studies were also conducted to determine the role of immunotherapy in the treatment of CCHF. A new immunoglobulin, Venin, which is specific to $\mathrm{CCHFV}$, has been prepared from the plasma pool of boosted donors through ethanol-polyethylene glycol fractionation and an ion-exchange purification step (65). However, in the case of CCHFV, the beneficial effects of immunotherapy are extremely limited $(20,66)$.

\section{Conclusion}

CCHF is harmful in the sense that it does not have any specific treatment. The only way to avoid this widespread infection is prevention. In a developing country such as Pakistan, the disease poses more serious effects due to inadequate resources. Due to the risks of disease in Pakistan, cross-border surveillance needs to be strengthened. Reinforcing the control measures to prevent the transmission of the disease to new areas is necessary. The animal and health sectors, by taking solid steps, can contribute to reduce the spread of this disease across the country. Awareness campaigns regarding risk factors and control measures can aid in apprising the public of the ill effects of this virus.

\section{References}

1. Ergönül O: Crimean-Congo haemorrhagic fever. Lancet Infect Dis 6: 203-214, 2006.

2. Mahzounieh M, Dincer E, Faraji A, Akin H, Akkutay AZ and Ozkul A: Relationship between Crimean-Congo hemorrhagic fever virus strains circulating in Iran and Turkey: Possibilities for transborder transmission. Vector Borne Zoonotic Dis 12 782-785, 2012

3. Bente DA, Forrester NL, Watts DM, McAuley AJ, Whitehouse CA and Bray M: Crimean-Congo hemorrhagic fever: History, epidemiology, pathogenesis, clinical syndrome and genetic diversity. Antiviral Res 100: 159-189, 2013.

4. Papa A, Sidira P, Larichev V, Gavrilova L, Kuzmina K, Mousavi-Jazi M, Mirazimi A, Ströher U and Nichol S: Crimean-Congo hemorrhagic fever virus, Greece. Emerg Infect Dis 20: 288-290, 2014.

5. Carroll SA, Bird BH, Rollin PE and Nichol ST: Ancient common ancestry of Crimean-Congo hemorrhagic fever virus. Mol Phylogenet Evol 55: 1103-1110, 2010.

6. Ergönül O: Crimean-Congo hemorrhagic fever virus: New outbreaks, new discoveries. Curr Opin Virol 2: 215-220, 2012.

7. Burt FJ and Goedhals D: Crimean-Congo haemorrhagic fever virus, an emerging and re-emerging pathogen. In: Zoonoses Infections Affecting Humans and Animals. Sing A (ed). Springer Netherlands, pp977-996, 2015.
8. Alam MM, Khurshid A, Sharif S, Shaukat S, Suleman RM, Angez $M$ and Zaidi SS: Crimean-Congo hemorrhagic fever Asia-2 Genotype, Pakistan. Emerging. Infect Dis J 19: 1017-1019, 2013.

9. Mild M, Simon M, Albert J and Mirazimi A: Towards an understanding of the migration of Crimean-Congo hemorrhagic fever virus. J Gen Virol 91: 199-207, 2010.

10. Hoogstraal H: The epidemiology of tick-borne Crimean-Congo hemorrhagic fever in Asia, Europe, and Africa. J Med Entomol 15: 307-417, 1979.

11. National Institute of Health, World Health Organization Pakistan: Seasonal awareness and alert letter (SAAL) for epidemic prone infectious diseases in Pakistan winter season. http://www.nih.org. $\mathrm{pk} /$ files/Newsletter/Seasonal\%20Awarness\%20and\%20Alert\%20 Letter\%20\%28SAAL\%29\%2029th\%20Issue.pdf. Accessed October 8, 2014.

12. Smego RA Jr, Sarwari AR and Siddiqui AR: Crimean-Congo hemorrhagic fever: Prevention and control limitations in a resource-poor country. Clin Infect Dis 38: 1731-1735, 2004.

13. Whitehouse C: Risk groups and control measures for Crimean-Congo hemorrhagic fever. In: Crimean-Congo Hemorrhagic Fever. Ergonul O and Whitehouse C (eds). Springer Netherlands, pp273-280, 2007.

14. WHO: Crimean Congo haemorrhagic fever: Fact Sheet No. 208 January, 2013. http://www.who.int/mediacentre/factsheets/fs208/en/. Accessed March, 2015.

15. Baloch S: Congo virus a fresh challenge for Balochistan. The Express Tribune, August 23, 2014.

16. Appannanavar SB and Mishra B: An update on Crimean-Congo hemorrhagic fever. J Glob Infect Dis 3: 285-292, 2011.

17. Hoogstraal H: African Ixodoidea. Ticks of the Sudan (with special reference to Equatoria Province and with preliminary reviews pf the genera Boophilus, Margaropus, and Hyalomma). Research Report NM 005.050.29.27, Department of the Navy, Bureau of Medicine and Surgery, Washington, DC, p1101, 1956.

18. Marriott AC and Nuttall PA: Molecular biology of nairoviruses In: The Bunyaviridae. Elliott R (ed). Springer, US, pp91-104, 1996.

19. Marriott AC and Nuttall PA: Large RNA segment of Dugbe nairovirus encodes the putative RNA polymerase. J Gen Virol 77: 1775-1780, 1996

20. Whitehouse CA: Crimean-Congo hemorrhagic fever. Antiviral Res 64: 145-160, 2004.

21. Palomar AM, Portillo A, Santibáñez P, Mazuelas D, Arizaga J, Crespo A, Gutiérrez Ó,Cuadrado JF and Oteo JA: Crimean-Congo hemorrhagic fever virus in ticks from migratory birds, Morocco. Emerg Infect Dis 19: 260-263, 2013.

22. Onishchenko GG, Tumanova IIU, Vyshemirskiǔ OI, Kuhn J, Seregin SV, Tiunnikov GI, Petrova ID, Tishkova FKH, Ospanov KS, Kazakov SV, et al: Study of virus contamination of Ixodes ticks in the foci of Crimean-Congo hemorrhagic fever in Kazakhstan and Tajikistan. Zh Mikrobiol Epidemiol Immunobiol 1: 27-31, 2005 (In Russian).

23. Alam MM, Khurshid A, Sharif S, Shaukat S, Rana MS, Angez $M$ and Zaidi SS: Genetic analysis and epidemiology of Crimean-Congo hemorrhagic fever viruses in Baluchistan province of Pakistan. BMC Infect Dis 13: 201, 2013.

24. Dohm DJ, Logan TM, Linthicum KJ, Rossi CA and Turell MJ: Transmission of Crimean-Congo hemorrhagic fever virus by Hyalomma impeltatum (Acari: Ixodidae) after experimental infection. J Med Entomol 33: 848-851, 1996.

25. Gonzalez JP, Camicas JL, Cornet JP, Faye O and Wilson ML: Sexual and transovarian transmission of Crimean-Congo haemorrhagic fever virus in Hyalomma truncatum ticks. Res Virol 43: 23-28, 1992.

26. Logan TM, Linthicum KJ, Bailey CL, Watts DM, Dohm DJ and Moulton JR: Replication of Crimean-Congo hemorrhagic fever virus in four species of ixodid ticks (Acari) infected experimentally. J Med Entomol 27: 537-542, 1990.

27. Shepherd AJ, Swanepoel R, Shepherd SP, Leman PA and Mathee O: Viraemic transmission of Crimean-Congo haemorrhagic fever virus to ticks. Epidemiol Infect 106: 373-382, 1991.

28. Dickson DL and Turell MJ: Replication and tissue tropisms of Crimean-Congo hemorrhagic fever virus in experimentally infected adult Hyalomma truncatum (Acari: Ixodidae). J Med Entomol 29: 767-773, 1992.

29. Labuda M and Nuttall PA: Tick-borne viruses. Parasitology 129: S221-S245, 2004.

30. Shepherd AJ, Leman PA and Swanepoel R: Viremia and antibody response of small African and laboratory animals to Crimean-Congo hemorrhagic fever virus infection. Am J Trop Med Hyg 40: 541-547, 1989. 
31. Nuttall PA and Labuda M: Tick-host interactions: Saliva-activated transmission. Parasitology 129: S177-S189, 2004.

32. Nuttall PA and Labuda M: Dynamics of infection in tick vectors and at the tick-host interface. Adv Virus Res 60: 233-272, 2003.

33. Jones LD, Davies CR, Steele GM and Nuttall PA: A novel mode of arbovirus transmission involving a nonviremic host. Science 237: 775-777, 1987.

34. Shepherd AJ, Swanepoel R, Leman PA and Shepherd SP: Field and laboratory investigation of Crimean-Congo haemorrhagic fever virus (Nairovirus, family Bunyaviridae) infection in birds. Trans R Soc Trop Med Hyg 81: 1004-1007, 1987.

35. Ergönül O, Celikbaş A, Dokuzoguz B, Eren S, Baykam N and Esener H: Characteristics of patients with Crimean-Congo hemorrhagic fever in a recent outbreak in Turkey and impact of oral ribavirin therapy. Clin Infect Dis 39: 284-287, 2004.

36. Bakir M, Ugurlu M, Dokuzoguz B, Bodur H, Tasyaran MA and Vahaboglu H; Turkish CCHF Study Group: Crimean-Congo haemorrhagic fever outbreak in Middle Anatolia: A multicentre study of clinical features and outcome measures. J Med Microbiol 54: 385-389, 2005

37. Ozkurt Z, Kiki I, Erol S, Erdem F, Yilmaz N, Parlak M, Gundogdu M and Tasyaran MA: Crimean-Congo hemorrhagic fever in Eastern Turkey: Clinical features, risk factors and efficacy of ribavirin therapy. J Infect 52: 207-215, 2006.

38. Butt Q: Another outbreak?: Congo virus threatens lives, warn doctors. The Express Tribune, October 7, 2013.

39. Begum F, Wisseman CL Jr and Casals J: Tick-borne viruses of West Pakistan. IV. Viruses similar to or identical with, Crimean hemorrhagic fever (Congo-Semunya), Wad Medani and Pak Argas 461 isolated from ticks of the Changa Manga Forest, Lahore District, and of Hunza, Gilgit Agency, W. Pakistan. Am J Epidemiol 92: 197-202, 1970.

40. Jamil B, Hasan RS, Sarwari AR, Burton J, Hewson R and Clegg C: Crimean-Congo hemorrhagic fever: Experience at a tertiary care hospital in Karachi, Pakistan. Trans R Soc Trop Med Hyg 99: 577-584, 2005

41. Malik S, Diju IU and Naz F: Crimean Congo hemorrhagic fever in Hazara division. J Ayub Med Coll Abbottabad 23: 90-92, 2011.

42. Athar MN, Baqai HZ, Ahmad M, Khalid MA, Bashir N, Ahmad AM, Balouch AH and Bashir K: Short report: Crimean-Congo hemorrhagic fever outbreak in Rawalpindi, Pakistan, February 2002. Am J Trop Med Hyg 69: 284-287, 2003.

43. Burney MI, Ghafoor A, Saleen M, Webb PA and Casals J: Nosocomial outbreak of viral hemorrhagic fever caused by Crimean Hemorrhagic fever-Congo virus in Pakistan, January 1976. Am J Trop Med Hyg 29: 941-947, 1980.

44. NIH and WHO: Guidelines for Crimean-Congo hemorrhagic fever (CCHF). September, 2013. http://www.nih.org.pk/ files/Guidelines/CCHF\%20guidelines\%20September\%202013. pdf. Accessed March, 2015.

45. WHO: Crimean-Congo haemorrhagic fever (CCHF) in Pakistan, 14 June 2013. In: Surveillance, Forecasting and Response. 2013. http://www.emro.who.int/index.html. Accessed April, 2015.

46. Abbas T, Younus M and Muhammad SA: Spatial cluster analysis of human cases of Crimean-Congo hemorrhagic fever reported in Pakistan. Infect Dis Poverty 4: 9, 2015.

47. Gozel MG, Bakir M, Oztop AY, Engin A, Dokmetas I and Elaldi N: Investigation of Crimean-Congo hemorrhagic fever virus transmission from patients to relatives: a prospective contact tracing study. Am J Trop Med Hyg 90:160-162, 2014.

48. van de Wal BW, Joubert JR, van Eeden PJ and King JB: A nosocomial outbreak of Crimean-Congo haemorrhagic fever at Tygerberg Hospital. Part IV. Preventive and prophylactic measures. S Afr Med J 68: 729-732, 1985.
49. Fisher-Hoch SP, Khan JA, Rehman S, Mirza S, Khurshid M and McCormick JB: Crimean Congo-haemorrhagic fever treated with oral ribavirin. Lancet 346: 472-475, 1995.

50. Simpson DI, Knight EM, Courtois G, Williams MC, Weinbren MP and Kibukamusoke JW: Congo virus: A hitherto undescribed virus occurring in Africa. I. Human isolations - clinical notes. East Afr Med J 44: 86-92, 1967.

51. Richmond JY and McKinney RW (eds): Biosafety in microbiological and biomedical laboratories. 4th edition. U.S. Government Printing Office, Washington, April, 1999.

52. Fisher-Hoch SP, Price ME, Craven RB, Price FM, Forthall DN, Sasso DR, Scott SM and McCormick JB: Safe intensive-care management of a severe case of Lassa fever with simple barrier nursing techniques. Lancet 2: 1227-1229, 1985.

53. Athar MN, Khalid MA, Ahmad AM, Bashir N, Baqai HZ, Ahmad M, Balouch AH and Bashir K: Crimean-Congo hemorrhagic fever outbreak in Rawalpindi, Pakistan, February 2002: Contact tracing and risk assessment. Am J Trop Med Hyg 72: 471-473, 2005

54. Centers for Disease Control and Prevention (CDC): Update: Management of patients with suspected viral hemorrhagic fever - United States. MMWR Morb Mortal Wkly Rep 44: 475-479, 1995.

55. Leblebicioglu H, Bodur H, Dokuzoguz B, Elaldi N, Guner R, Koksal I, Kurt H and Senturk GC: Case management and supportive treatment for patients with Crimean-Congo hemorrhagic fever. Vector Borne Zoonotic Dis 12: 805-811, 2012.

56. Lloyd E and Perry H: Infection control for viral haemorrhagic fevers in the African health care setting. Centers for Disease Control and Prevention and World Health Organization, Infection Control for Viral Haemorrhagic Fevers in the African Health Care Setting.Atlanta, Centers for Disease Control and Prevention, pp1-198, 1998.

57. Vanhomwegen J, Alves MJ, Zupanc TA, Bino S, Chinikar S, Karlberg H, Korukluoğlu G, Korva M, Mardani M, Mirazimi A, et al: Diagnostic assays for Crimean-Congo hemorrhagic fever. Emerg Infect Dis 18: 1958-1965, 2012.

58. Stachelhaus DT: Efficient tools for sensitive and specific detection of infections with Chikungunya virus, Crimean-Congo hemorrhagic fever virus and other viruses causing emerging diseases. Ascenion reference number TO 12-00042.

59. CDC: http://www.cdc.gov/vhf/crimean-congo/diagnosis/index. html. Accessed February 21, 2015.

60. Oncü S: Crimean-Congo hemorrhagic fever: An overview. Virol Sin 28: 193-201, 2013

61. Buttigieg KR, Dowall SD, Findlay-Wilson S, Miloszewska A, Rayner E, Hewson R and Carroll MW: A novel vaccine against Crimean-Congo haemorrhagic fever protects $100 \%$ of animals against lethal challenge in a mouse model. PLoS One 9: e91516, 2014.

62. Soares-Weiser K, Thomas S, Thomson G and Garner P: Ribavirin for Crimean-Congo hemorrhagic fever: Systematic review and meta-analysis. BMC Infect Dis 10: 207, 2010.

63. Ascioglu S, Leblebicioglu $\mathrm{H}$, Vahaboglu $\mathrm{H}$ and Chan KA: Ribavirin for patients with Crimean-Congo haemorrhagic fever: A systematic review and meta-analysis. J Antimicrob Chemother 66: 1215-1222, 2011.

64. Ergonul O: Treatment of Crimean-Congo hemorrhagic fever. Antiviral Res 78: 125-131, 2008.

65. Vassilenko SM, Vassilev TL, Bozadjiev LG, Bineva IL and Kazarov GZ: Specific intravenous immunoglobulin for Crimean-Congo haemorrhagic fever. Lancet 335: 791-792, 1990.

66. Flick R and Whitehouse CA: Crimean-Congo hemorrhagic fever virus. Curr Mol Med 5: 753-760, 2005. 